\title{
ENSINO FUNDAMENTAL DO PARANÁ: REVISITANDO A QUALIDADE E A AVALIAÇÃO
}

\author{
Doralice Aparecida Paranzini Gorni*
}

RESUMO. Este artigo apresenta os resultados de um estudo comparativo do rendimento dos alunos das $4^{\text {as }}$ séries do Ensino Fundamental do Paraná nas avaliações levadas a efeito pela Secretaria de Educação em 1997 e 1998 . O estudo foi realizado a partir dos percentuais de acerto dos alunos nas diferentes provas. Os resultados apontam evidências de melhora no desempenho em Matemática, Ciências e Redação e queda apenas em Português. Apesar disto, esses resultados não atingem níveis satisfatórios, pois em aproximadamente $50 \%$ das provas um número elevado de alunos alcançou percentuais inferiores à média. Esta tendência revela a necessidade de realização de uma avaliação do sistema para além do rendimento do aluno, com vistas à identificação e superação das suas reais fragilidades e deficiências.

Palabras clave: Ensino Fundamental do Paraná, qualidade da educação, avaliação da educação.

\section{ELEMENTARY SCHOOLS OF PARANÁ STATE: REVISITING QUALITY AND EVALUATION}

\begin{abstract}
This article presents the results of a comparative study on the evaluations of $4^{\text {th }}$ grade students of Elementary Schools from Paraná State. The evaluations were carried out by the Education Department in 1997 and 1998 . The study was accomplished based on the percentile of the students achievement in the different tests. The results show improvement in mathematics, sciences and composition and a decline only in Portuguese. In spite of this, the results do not reach satisfactory levels, because in approximately $50 \%$ of the tests a high number of students reached percentile inferior to the average. This tendency reveals the need of a review on the system itself, an evaluation beyond the student's performance, with views to the identification and solution of their real deficiencies and vulnerability.
\end{abstract}

Key words: Elementary School of Paraná, quality of education, evaluation of the education.

O processo de abertura democrática do Brasil, iniciado na década de 1980, resultou, num primeiro momento, na eleição de governadores de partidos de oposição ao Governo Federal em vários estados da federação. Em decorrência, foram introduzidas mudanças no sistema educacional destes estados, com vistas à democratização e à melhoria da qualidade da educação pública.

Transcorridos aproximadamente dez anos, deparamo-nos, no Paraná, com a inexistência de informações sistematizadas acerca do sistema educacional, além da dificuldade de acesso a informações atualizadas sobre o mesmo sistema nas suas diferentes instâncias. Este fato, no final da década de 1990, motivou a realização de um estudo que teve como objetivo contribuir para aprofundar $o$ conhecimento acerca da realidade concreta do ensino fundamental paranaense.

A realização desse estudo também se justificou pelo entendimento de que o conhecimento da realidade é um instrumento de vital importância para os diferentes profissionais que atuam no contexto educacional e buscam a transformação da realidade social e das instituições em que se inserem.

A pesquisa abarcou, além de outras estratégias, a realização de um estudo comparativo dos resultados de rendimento dos alunos das $4^{\text {as }}$ e $8^{\text {as }}$ séries do Ensino Fundamental do Paraná no período de 1995 a 1997, o qual permitiu refletir acerca da qualidade do sistema e das possibilidades de superação das dificuldades nele existentes.

* Professora Associada do Departamento de Psicologia Social e Institucional docente do Mestrado em Educação da Universidade Estadual de Londrina. Mestre em Psicologia da Educação / PUCSP. Doutora em Educação/UNESP.

Psicologia em Estudo, Maringá, v. 9, n. 2, p. 309-318, mai./ago. 2004 
Dando seguimento a esse estudo, nova pesquisa, realizada de 2000 a 2003, objetivou a atualização dos dados existentes, bem como a analisar em que medida alguma melhoria de qualidade do sistema havia sido alcançada.

Ao relatar os resultados desse último trabalho, Revisitando a qualidade e a avaliação, pretende-se disponibilizar alguns dados que contribuem para as reflexões e o aprofundamento do conhecimento acerca do Ensino Fundamental do Paraná. Este conhecimento, adicionado ao do contexto e da realidade em que se inserem as diferentes instituições educacionais e ao conhecimento dos determinantes históricos, sociais, políticos e econômicos que permearam o desenvolvimento da educação brasileira, é imprescindível para o processo de formação e o trabalho dos diferentes profissionais que atuam no contexto escolar, na medida em que pode subsidiar o desenvolvimento de ações que concretamente possam responder às demandas e necessidades existentes nestes contextos.

Com este intuito, o texto traz inicialmente uma breve revisão acerca do sistema educacional, da qualidade e da avaliação da educação, para, na seqüência, apresentar o relato da pesquisa desenvolvida e as considerações da autora acerca das perspectivas do sistema, tendo em vista a forma como qualidade e avaliação vêm sendo atreladas nas políticas educacionais e nas ações governamentais.

\section{A REORGANIZAÇÃO DA EDUCAÇÃO BRASILEIRA APÓS 1980}

Os movimentos e propostas de novas políticas educacionais que marcaram a década de 1980, após o início do processo de abertura democrática do país, os quais ocorreram, num primeiro momento, no âmbito dos estados em que foram eleitos governadores de partidos de oposição ao Governo Federal, permitiram que esses estados buscassem simultaneamente focalizar e encontrar soluções para seus respectivos problemas educacionais.

Embora independentes, os processos desenvolvidos nesses estados possuíam elementos comuns, os quais contribuíram para a construção do pensamento que, nos anos 1990, permearia as reflexões e influenciaria os rumos da reforma do sistema educacional brasileiro.

Em decorrência do embate político resultante, o processo de tramitação e aprovação da Lei 9394/96 revela, como aponta Saviani (1997), os limites e as perspectivas delineadas para a educação brasileira. Ao dispor sobre a elaboração das Diretrizes Curriculares
Nacionais, que se consolidaram no contexto das escolas com a implantação dos Parâmetros Curriculares Nacionais do Ensino Fundamental e Médio, do Referencial Curricular Nacional da Educação Infantil e das Diretrizes Nacionais dos Cursos Superiores, a Lei de Diretrizes e Bases da Educação Nacional (LDB) alterou a reestruturação dos sistemas educacionais estaduais ${ }^{1}$, iniciada anteriormente, os quais passaram a ser canalizados e ajustados às novas bases nacionais.

Sob este enfoque, a alteração crucial ocorrida no processo de reestruturação iniciado no âmbito dos estados, consistiu em que as ações subsidiadas na perspectiva histórico-crítica passaram a dividir espaço com programas e orientações de tendência neoliberal que, ao longo do tempo, alteraram substancialmente seu desenvolvimento.

Por esta razão, o conhecimento e a análise do processo de inserção do neoliberalismo no bojo da educação nacional e da sociedade brasileira, recémdemocratizada, passaram a ser instrumentos importantes tanto para o processo de formação como para o aperfeiçoamento e a atualização dos profissionais que atuam nas diferentes instâncias do sistema educacional, quando se visa contribuir para a melhoria da qualidade da educação desenvolvida, principalmente, no âmbito do sistema público de ensino.

Isto se deve principalmente ao fato de que a realidade é permeada pelos padrões históricos, culturais, políticos e econômicos da sociedade em que se insere, assim como pelas diversas formas de pensamento manifestas em seus diferentes movimentos e momentos. Neste sentido, os estudos de Ghiraldelli Jr. (1992) e Saviani (1997, 2000) permitem avaliar tanto a influência dos fatores arrolados acima no sistema educacional brasileiro a partir do início do século XX, quanto seus impactos na sociedade atual.

Tal análise evidencia ainda que uma reforma educacional era não só bem-vinda mas também necessária; no entanto, conforme demonstra Valente (2002), em nosso país, a reforma dos anos 1990 foi introduzida e traçada gradual e pontualmente, de forma que muitos integrantes do próprio sistema não se deram conta de seu caráter amplo e global.

Foi neste sentido que começamos a nos deparar, a partir de 1995, com a alteração dos rumos da reestruturação da educação introduzida no Paraná a partir de 1985. Sob a égide do aporte neoliberal e da

1 O detalhamento e análise do processo de reestruturação do Ensino Fundamental do Paraná encontra-se em Gorni (1999). 
influência dos órgãos financiadores internacionais, especialmente do Banco Mundial, foram introduzidos novos elementos no contexto escolar.

Em decorrência, alguns dos princípios e metas que sustentavam o projeto de reestruturação em andamento, como os ideais de formação do aluno enquanto ser e cidadão, de promoção do desenvolvimento humano, de autonomia e de descentralização do sistema mantiveram-se nos documentos oficiais, e ao mesmo tempo foram introduzidas novas orientações que, calcadas nas teorias econômicas, instituíam a avaliação dos resultados do sistema mediante a medida do rendimento dos alunos, da capacidade de certificação do sistema e da otimização da relação custo-benefício.

A despeito da distância e distinção das perspectivas em que se apoiavam, as duas vertentes foram teoricamente "agregadas" embora prevalecessem os princípios e diretrizes das tendências neoliberais na normatização e orientação do funcionamento do sistema.

Diante deste quadro, não podemos deixar de resgatar as questões acerca do porquê, para que e a quem serve o formato de reforma proposto. Cabe-nos ainda refletir sobre as razões por que a abertura democrática da sociedade brasileira tem se refletido tão pouco e lentamente no processo de transformação do sistema educacional.

Partindo destas questões, entendemos, conforme exposto em Gorni (1999; 2002) e Gorni, Hoshiro, Kuasne, e Mattei (2003), que a formação política dos profissionais atuantes no contexto escolar é elemento diferencial para sua conscientização e reflexão acerca de seu papel e função social. Contribui para essa formação o conhecimento, a análise e a reflexão acerca da realidade e das proposições vigentes no sistema educacional, na medida em que esses fatores constituem atualmente um importante instrumento de que os educadores e os diferentes profissionais atuantes no contexto escolar e nas demais instâncias do sistema educacional podem dispor quando almejam contribuir para a transformação desse contexto, no sentido de busca de melhoria de qualidade. Sob este prisma, a ação reflexiva deve ser parte integrante de sua formação e práxis ${ }^{2}$.

Disto se depreende que a transformação do sistema educacional não pode prescindir da responsabilidade e do compromisso de cada um e de

2 A práxis educativa é, por excelência, a investigação das possibilidades e dificuldades, tanto de quem se coloca na condição de aprendiz como daquele que, além de aprender, coordena, desenvolve e organiza saberes e modalidades na relação educativa, conforme destaca Resende (2001, p.248). todos os envolvidos. Neste sentido, como destaca Freire (1987), temos todos a aprender e ensinar, colocando em comunhão o que somos e sabemos.

Dizendo de outra forma, a única possibilidade de transformação do sistema educacional, no sentido de sua melhoria de qualidade, do ponto de vista do grande contingente de pessoas que dele necessita para conquistar sua condição de humanidade e cidadania, se encontra na sua capacidade de superação do modelo neoliberal imposto pela própria reforma.

\section{UM BREVE OLHAR SOBRE A QUALIDADE DA EDUCAÇÃO}

A preocupação com a qualidade da educação tem canalizado esforços de parcela significativa de estudiosos; parcela que, focalizando a educação por diferentes prismas, tem contribuído significativamente para a evolução do entendimento da qualidade intrínseca ao processo pedagógico como sendo decorrente não de um fator específico, mas da combinação ótima de um conjunto de fatores existentes no contexto intra e extra-escolar.

Deste ponto de vista, a qualidade da educação é específica a cada contexto, implicando e dependendo da capacidade de integração das dimensões políticoideológica e técnico-pedagógica, conforme destaca Aguerrondo (1993). Isto significa que a qualidade da educação expressa o resultado do conjunto das opções realizadas - tanto de caráter ideológico quanto pedagógico - que caminham por trás das tomadas de decisões, das avaliações, do estabelecimento de prioridades, e, por fim, do estabelecimento das políticas educativas.

Neste sentido, segundo o autor, o conceito de qualidade está cheio de possibilidades: a) é complexo e totalizante; b) é social e historicamente determinado; c) se constitui em imagem-objeto de transformação educacional; e, d) se constitui no padrão de controle de eficiência do serviço.

Com o intuito de aprofundar a investigação acerca de como os diferentes elementos interferem na qualidade educacional, muitos estudos têm sido desenvolvidos. Dentre eles destacamos o de Reid, Hopkins e Holley (citado por Nóvoa, 1995), que aponta a autonomia das escolas, a liderança organizacional, a articulação curricular, a otimização do tempo, a estabilidade profissional, a formação profissional, a participação dos pais e o reconhecimento público e apoio das autoridades como fatores que contribuem para a qualidade do trabalho pedagógico. 
Além destas características, Good (1995) aponta como relevantes: a gestão centrada na qualidade do ensino; a importância primordial das aprendizagens acadêmicas; a existência de um clima tranqüilo e bemorganizado, propício ao ensino e à aprendizagem; o comportamento dos professores transmitindo expectativas positivas quanto à possibilidade de todos os alunos obterem um nível mínimo de competência, e a utilização dos resultados dos alunos como base para a avaliação de programas e currículos.

De maneira complementar, Purkey e Smith (1983) destacam o planejamento conjunto das relações colegiais; o sentimento de pertença a uma comunidade; o estabelecimento de metas de maneira clara e objetiva; as expectativas elevadas; a ordem e a disciplina.

Para Candeias (1995), também são relevantes as relações pedagógicas e a existência de valores consensuais. Em outras palavras, é muito importante que todos integrem as funções de concepção, avaliação e inovação do trabalho das escolas, assumindo como uma das principais tarefas o "trabalho de pensar o trabalho", conforme Mintzberg (citado por Nóvoa, 1995).

Esta asserção corrobora a proposição de Rustin (citado por Mezomo, 1997), de que a qualidade é sempre fruto de um esforço inteligente e da vontade de produzir algo superior: é construída etapa por etapa e decorre de um compromisso real de todos os envolvidos no processo.

Do exposto acima, pode-se concluir que o empreendimento de qualquer iniciativa em prol da melhoria da qualidade da educação está fortemente condicionado à presença, nas diferentes instâncias do contexto educacional, de pessoas que compactuem com os objetivos e ideais educacionais, pois, conforme concluiu Candeias (1995), a forma que temos de pensar e praticar a educação está indissoluvelmente ligada às representações que temos da vida, da realidade e do processo de formação do ser humano.

Deste ponto de vista, os parâmetros e ideais de qualidade explicitados nas atuais políticas educacionais, embora contemplem os ideais propugnados no interior do contexto educacional, ao se voltarem predominantemente às regras e indicadores do mercado tornam-se contraditórios e conflitantes com suas próprias proposições e, desta forma, pouco ou quase nada introduzem de espaço real de transformação e superação dos problemas existentes no sistema.

\section{Recolocando a avaliação}

Diante da pluralidade das realidades que o processo avaliativo deve contemplar, as avaliações verdadeiras são, segundo Penna Firme (1994), as que subsidiam decisões e procuram resolver os problemas e preocupações dos que atuam diretamente nos projetos, programas, etc. Desta forma, a avaliação deve ser utilizada com propriedade e criticidade, adotando e elaborando instrumentos capazes de captar todos os aspectos que se fizerem presentes no curso.

Sob este enfoque, a avaliação deve ser prioritariamente desenvolvida no contexto educacional e tomada na sua forma ampla, tanto por parte dos órgãos oficiais como pelos próprios docentes e educadores em geral, como forma de garantir o resgate da qualidade.

Nesta perspectiva, a avaliação educacional não mais tem seu interesse circunscrito ao aluno e seu rendimento, ao desenvolvimento de atitudes e interesses, que constituem o produto do processo institucional que ocorre na escola, mas amplia-se do âmbito da microavaliação para uma área bem mais ampla, que constitui o campo da macroavaliação, segundo Payne (citado por Vianna, 1997).

Interessante notar, como destaca Simons (1993), que, ao alargar seu campo de visão aos processos e contextos de implementação da avaliação, procurando uma melhor compreensão dos problemas educacionais que persistem ao longo do tempo e uma base sólida para estratégias de intervenção mais eficazes, os educadores tomaram consciência da complexidade de seu campo de atuação e da necessidade de definir e avaliar a prioridade de alguns problemas do mundo moderno.

Para tanto, a avaliação educacional deve envolver pelo menos três vertentes: a) a avaliação que ocorre ao nível das proposições e políticas do sistema; b) a avaliação da escola enquanto instância que operacionaliza as proposições do sistema e, c) a avaliação do aluno na escola.

Estas três modalidades, quando inter-relacionadas, possibilitam a avaliação do sistema educacional na sua totalidade, adquirindo, segundo Vianna (1997), um papel importante na crítica para a transformação da escola, de seus currículos e programas.

Para o autor, o sentido desta transformação deve se dar em consonância com os ideais da qualidade de educação, postos enquanto preocupação de todos os segmentos sociais, visto que a educação, entendida como um valor social, extrapola os interesses circunstanciais de grupos isolados, passando a ser preocupação da sociedade em geral.

No que se refere à avaliação realizada na escola esta afirmação é também verdadeira, principalmente porque, em função dos estudos realizados nas décadas de 1980 e 1990, esta passou a ser vista como a vilã do 
processo educativo, conforme destaca Rampazzo (2002), sendo considerada excludente e seletiva.

Em seu estudo sobre avaliação, Perrenoud (1999) ocupou-se da explicitação das causas e consequiências do fracasso escolar dos alunos, visando apontar caminhos que pudessem contribuir para sua superação. Neste sentido, o autor ressalta a necessidade de modificar a avaliação que está sendo realizada nas escolas, alertando para o fato de que mudanças na avaliação implicam em outras mudanças no sistema escolar, uma vez que ela é o centro de uma abordagem sistemática que envolve outros elementos como: relação família-escola; organização das turmas; didática e métodos de ensino; contrato pedagógico; trabalho discente; política institucional; planos de estudos; sistemas de seleção e orientação; satisfação pessoal e profissional.

$\mathrm{Na}$ perspectiva do autor, ações propostas em nível de instrumentos, formas de avaliar ou condução da avaliação não são suficientes para promover mudanças no cenário educativo, quando se realizam mediante ações isoladas. Sua proposta consiste em que a avaliação realizada nas escolas atribua menos importância à classificação, centrando-se mais na regulação das aprendizagens. Deve então se processar de maneira formativa, deslocando-se para o processo de ensino e aprendizagem e considerando tudo que possa ajudar o aluno a aprender melhor, mediante a investigação das competências que estes já tenham adquirido, as em desenvolvimento e as que ainda necessitem ser construídas.

Perrenoud (1999) entende como formativa "toda prática de avaliação contínua que pretenda contribuir para melhorar as aprendizagens em curso, qualquer que seja o quadro e qualquer que seja a extensão concreta da diferenciação do ensino" (p.78). Desta forma, a avaliação deve centrar-se nas aprendizagens do aluno de forma direta e imediata inserindo-se no processo de ensino e aprendizagem que acontece na escola diariamente, e não em momentos estanques, preparados cuidadosamente para este fim. Neste sentido, ela é contínua, embora nem toda avaliação contínua seja formativa, já que nem todas possuem a finalidade de contribuir para a progressão da aprendizagem.

O que o autor propõe, enfim é, conforme a expressão utilizada pela psicologia, a utilização de instrumentos que permitam fornecer feedback aos professores e alunos ao longo do processo, como estratégia de busca de aprimoramento do processo de ensino e aprendizagem.

Corroborando esta proposição, Hadji (2001) enfatiza que a avaliação se inscreve em um processo educativo específico, não precisando, necessariamente, conformar-se a nenhum padrão metodológico. Basta apenas informar aos atores do processo educativo. Quando informa, permite uma regulação das aprendizagens e acrescenta-lhes uma função corretiva, possibilitando uma variabilidade didática, ou seja, a alteração do processo de ensino e aprendizagem.

Tendo em vista a inexistência de um modelo diretamente aplicável de avaliação formativa, Hadji (2001) sugere que a construção de uma prática de avaliação nestes moldes se respalde nos objetivos da prática educativa, nas modalidades dessa prática, nas condições técnicas e na deontologia do trabalho do avaliador. Entretanto, adverte para a necessidade de o professor ter coragem para ousar falar e julgar, colocando seu julgamento a serviço do aluno, permitindo-lhe torná-lo soberano e não se submeter.

Parece evidente a necessidade de superação da avaliação tradicional, centrada em aspectos quantitativos para a concretização da avaliação formativa. Luckesi (1996), Hoffmann (1991, 1993), Vasconcelos (1994, 1995), destacam e refletem sobre as questões que têm permeado a avaliação escolar e como esta tem contribuído para o insucesso do aluno e o fracasso da escola.

Neste sentido, Vasconcelos compreende que o compromisso do professor é com a aprendizagem de todos os alunos, e considera que a mudança na ação avaliativa é um desafio a ser enfrentado, após uma tomada de consciência do problema político envolvido na situação escolar como sendo um determinante na opção por qualquer prática. Para ele as mudanças de postura se iniciam pelo ato avaliativo, numa relação com as idéias e a realidade, através da reflexão da própria ação.

De maneira complementar, o autor considera essencial o redimensionamento do conteúdo da avaliação com ênfase ao enfoque reflexivo, relacional e compreensivo, e a alteração da postura do professor diante dos resultados da avaliação, tomando decisões sobre os caminhos a seguir para a superação dos problemas e dificuldades constatados e desenvolvendo uma prática diagnóstica, a fim de identificar as necessidades do aluno e intervir para superá-las.

Para atuar neste sentido os educadores precisam contar com o auxílio e apoio dos profissionais que integram as equipes técnico-pedagógicas e administrativas das escolas. Neste sentido, a ação integrada de todos os atores que atuam no contexto escolar pode contribuir tanto para otimizar o desenvolvimento do aluno enquanto ser humano e ser social quanto para oportunizar-lhe as condições necessárias à apropriação do conhecimento historicamente construído. 
Sob esta perspectiva, para que a melhoria de qualidade do processo educacional possa se concretizar há que se superar o isolamento do trabalho docente e aprofundar os processos coletivos de reflexão e análise acerca da prática pedagógica, com vistas ao seu redimensionamento no interior das escolas. Como destacam Zabala (1998) e Sa Chaves (2002), é a reflexão sobre a ação que sustenta o sucesso do processo de ensino e aprendizagem.

Por outro lado, são também necessárias mudanças do ponto de vista do sistema,. Dentre elas, é imprescindível a submissão das políticas, dos programas e dos projetos educacionais a um processo de avaliação contínua com vistas ao seu aprimoramento, em substituição à predominante avaliação de sistema e da qualidade da educação mediante a avaliação pontual e de produto, pautada no rendimento dos alunos e na capacidade de certificação dos mesmos ao término de cada ciclo de estudos.

Desta forma, ao mesmo tempo que a avaliação do aluno na escola não tem dado conta de garantir a melhoria de qualidade do trabalho pedagógico desenvolvido, também as avaliações do sistema, realizadas tanto em nível estadual quanto federal, não têm constituído instrumento de aprimoramento do sistema e de revisão de políticas propostas que, muitas vezes inadequadas, só têm feito perpetuar as mazelas existentes no interior do sistema.

\section{A PESQUISA REALIZADA}

A pesquisa relatada integra um estudo desenvolvido em duas frentes de ação: 1) a atualização dos resultados da avaliação de rendimento dos alunos das $4^{\mathrm{as}}$ séries do Ensino Fundamental do Paraná, e 2) a investigação da avaliação realizada por professoras de $4^{\mathrm{a}}$ série de três escolas estaduais, durante o ano $2000^{3}$.

A avaliação de rendimento dos alunos consistiu em um estudo comparativo do resultado obtido pelos mesmos no período de 1995 a 1998, e teve como objeto central de análise os resultados das avaliações realizadas no estado pela Secretaria de Estado da Educação - SEED/PQE.

Optou-se pela realização do presente estudo diante da inexistência de um trabalho desta natureza no âmbito do sistema e, em decorrência disto, da dificuldade de avaliar a medida em que as propostas e ações (administrativas, políticas e pedagógicas) implementadas no período em questão foram ou não

3 Esta linha de ação será objeto de outro texto, tendo em vista sua extensão. bem-sucedidas. Para a elaboração deste artigo, foram considerados os resultados de 1997 e 1998, tendo-se em vista que os demais anos foram detalhados nos trabalhos anteriores da autora, conforme já mencionado.

\section{RESULTADOS E DISCUSSÃO}

Os resultados da avaliação de rendimento dos alunos a que se refere o presente

item foram obtidos pelo Programa de Avaliação do Sistema Educacional do Paraná, instituído pela Resolução n. ${ }^{\circ}$ 2270/95 GS/SEED, que compreende a avaliação do rendimento escolar no Ensino Fundamental e Médio das escolas públicas estaduais.

$\mathrm{Na}$ presente investigação foram consideradas as avaliações realizadas junto aos alunos das $4^{\text {as }}$ séries do EF, conforme cronograma apresentado no Tabela 1. Isto se deveu, diferentemente da proposição inicial, ao fato de que, em duas ocasiões distintas (1996 e 1998) a Secretaria de Estado alegou não poder disponibilizar os resultados obtidos junto aos alunos das $8^{\text {as }}$ séries, por não possuí-los, devido a problemas de ordem técnica e financeira que implicaram na sua perda e não-obtenção de maneira integral junto à prestadora de serviços, respectivamente. Estes fatos ilustram algumas das razões da dificuldade de sistematização e acesso aos dados do sistema.

Tabela 1. Cronograma de realização das avaliações das $4^{\text {as }}$ séries

\begin{tabular}{lll}
\hline 1995 & 1997 & 1998 \\
\hline Português & Português & Português \\
Matemática & Matemática & Matemática \\
Redação & Redação & Redação \\
-- & Ciências* & Ciências* \\
\hline
\end{tabular}

* Disciplina avaliada a partir de 1997.

Como pode ser observado, em 1996 não foi realizada a avaliação de rendimento dos alunos das $4^{\text {as }}$ séries. Nesse ano, foram avaliados apenas os alunos das $8^{\text {as }}$ séries.

Cabe destacar ainda que a partir de 1998 as avaliações passaram a ser realizadas a cada dois anos, conforme sugestão contida em (Gorni, 1999). Desta forma, novas avaliações ocorreram em 2000 e 2002; porém seus resultados não puderam ser obtidos, junto à SEED/Pr, em tempo hábil para sua inclusão no presente estudo.

Com relação à faixa etária dos alunos, a análise abarca todo o período da investigação, conforme consta na Figura 1. 


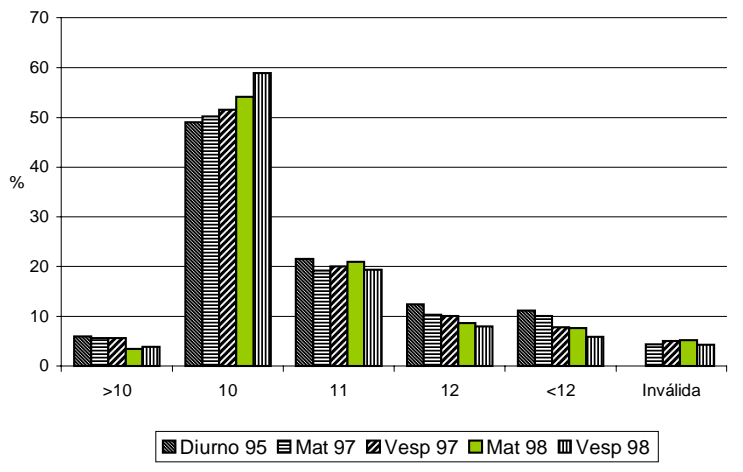

* A categoria inválida foi introduzida em 97.

Figura 1. Distribuição dos alunos da $4^{\mathrm{a}}$ série por faixa etária (95-98)

A Figura 1 permite observar o aumento gradual do número de alunos das $4^{\text {as }}$ séries na idade adequada e a redução, no decorrer do tempo, do número de alunos em idade superior e inferior a dez anos. Este dado pode ter várias explicações, dentre as quais destacamos os efeitos do programa de adequação idade-série. No entanto, não podemos afirmar, com os dados de que dispomos, que isto se deva a este fator.

Apesar do aumento do número de alunos na faixa etária adequada à série, ainda existiam, em 98, aproximadamente $40 \%$ de alunos com idade superior à desejável, nas escolas públicas estaduais. Mesmo assim, em relação à pesquisa anterior, observa-se uma redução, de aproximadamente $10 \%$, no número de alunos com idade acima da desejável, o que é um resultado positivo.

Com relação ao rendimento dos alunos das $4^{\text {as }}$ séries nas diferentes disciplinas e nas diferentes avaliações realizadas, efetuou-se a análise comparativa entre médias, com base nos dados obtidos junto à SEED. Na sequiência, apresentamos a análise comparativa do grau de facilidade das provas, estabelecido a partir do total de acertos obtido pelos alunos, nas diferentes situações de avaliação.

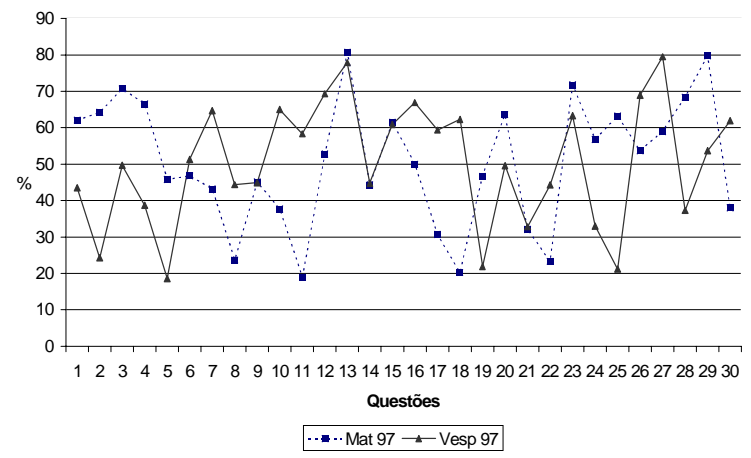

Figura 2. Porcentagem de acerto em Português Mat 97 e Vesp 97

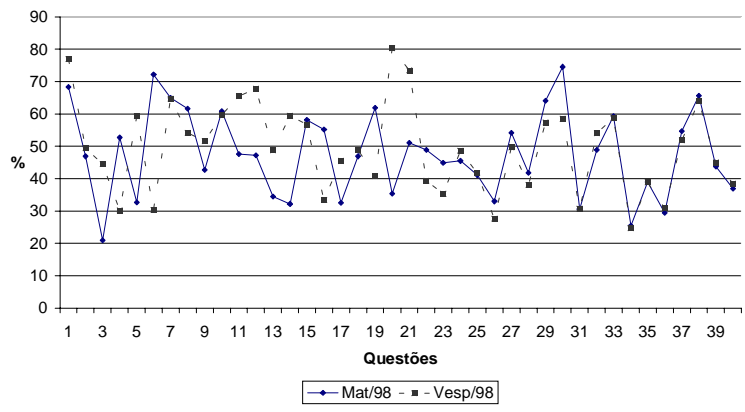

Figura 3. Porcentagem de acertos dos alunos em Português, no ano de 1998

As figuras permitem observar que, nas duas avaliações, os alunos obtiveram de 20 a $80 \%$ de acertos, apresentando menor grau de dispersão de respostas em 98.

A Figura 2 permite observar ainda que em 97 a prova continha 30 questões e que os alunos dos dois turnos obtiveram resultados semelhantes em quatro delas. Nas demais, os resultados foram distintos, sendo que o matutino obteve percentuais inferiores em 12 questões e superiores também em 12 questões. Já os resultados obtidos em 1998 apresentam-se difusos nas primeiras 30 questões; no entanto, nas dez questões finais, houve praticamente uma coincidência no desempenho dos alunos dos dois períodos, conforme os dados da Figura 3.

A análise do desempenho dos alunos permite observar que, em ambas as avaliações, os alunos do turno matutino obtiveram uma leve vantagem sobre os do vespertino. Mesmo assim, os alunos do matutino, que haviam obtido percentual de acerto superior a 60 em $40 \%$ da prova em 97 , obtiveram-no apenas $22,5 \%$ em 98. No que se refere aos alunos vespertinos foram observados resultados semelhantes, caindo de 33.33 para 30\% seu rendimento na avaliação de 98.

Os resultados obtidos em matemática foram concentrados nas Figuras 4 e 5.

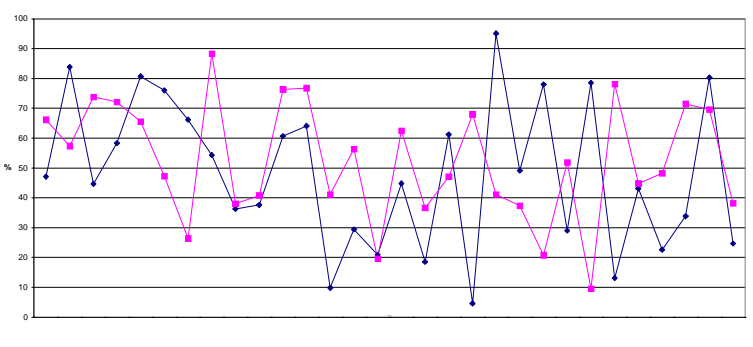

$\rightarrow$ Mat $97-$ - Vesp 97

Figura 4. Comparação da porcentagem de acertos em matemática dos alunos da $4^{\mathrm{a}}$. Série Mat 97 e Vesp 97 


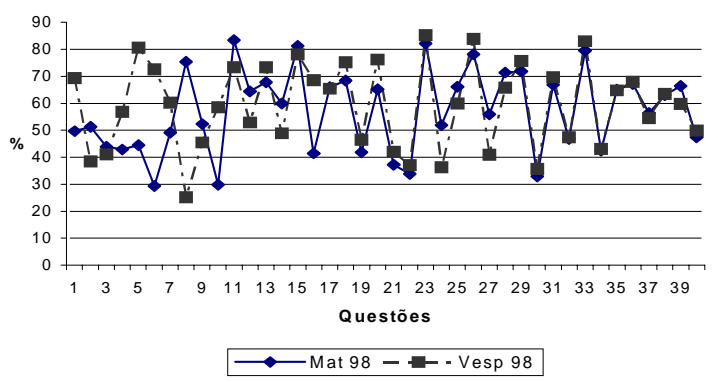

Figura 5. Porcentagem de acerto em matemática em 98

Distintamente do rendimento em Português, em Matemática as respostas que atingiram índices abaixo de 10 e superiores a $90 \%$, em 97, tiveram seus índices inferiores aumentados para próximo de $20 \%$ em 98 , denotando uma melhora no rendimento. As duas figuras permitem ainda observar que o rendimento dos alunos em 98 permitiu traçar uma curva mais homogênea, revelando uma sobreposição quase perfeita do rendimento dos alunos dos dois turnos nas questões finais da prova.

Apesar da aparente semelhança de desempenho, uma análise mais detalhada da figura 5 revela uma diferença significativa entre eles, uma vez que os alunos do matutino alcançaram percentual superior a $60 \%$ em $40 \%$ da prova, contra $52 \%$ do vespertino. Tais resultados superaram os obtidos em 97 por ambas as turmas, na medida em que estes se localizaram nas casas de 36,6 e 40\%, respectivamente, conforme figura 4 .

A melhora no rendimento do turno matutino pode ainda ser observada pelo aumento do percentual de acerto (superior a 60\%), de $36.66 \%$ em 97 para $50 \%$ em 98.

Análise similar dos resultados dos alunos do vespertino revela uma melhora no seu rendimento, uma vez que estes acertaram, com percentual superior a $60 \%, 40 \%$ da prova em 97 e $57.5 \%$ em 98 .

Os resultados obtidos em Ciências estão concentrados nas Figuras 6 e 7.

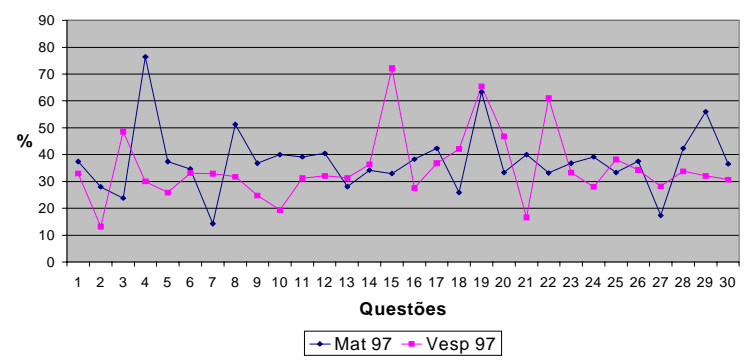

Figura 6. Porcentagem de acerto em Ciências - Mat 97 Vesp 97

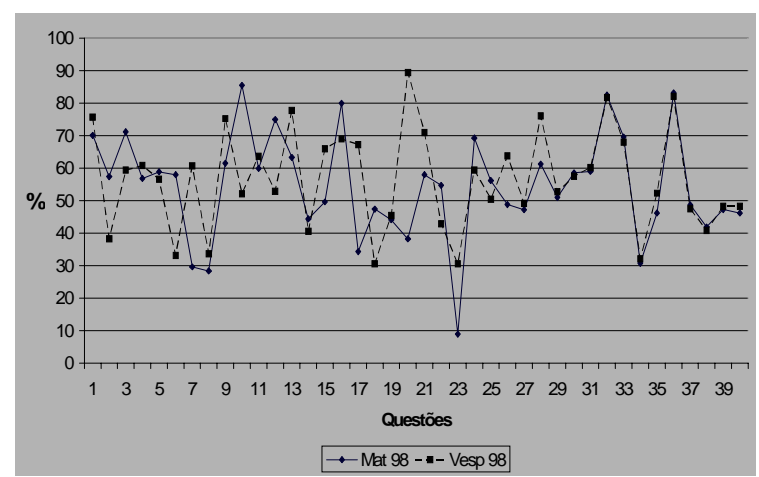

Figura 7. Porcentagem de acerto em Ciências em 1998

A Figura 6 permite fazer uma análise semelhante à realizada em relação a Matemática, no que se refere à difusão das respostas nas primeiras questões e à semelhança do rendimento dos alunos na avaliação de 98 . A figura permite ainda observar uma leve vantagem para os alunos do período vespertino, em 97.

No que se refere ao rendimento dos alunos em 98, a Figura 7 permite observar percentuais superiores aos obtidos em 97. Pode-se constatar ainda que o matutino alcançou percentual de $60 \%$ ou superior em $25 \%$ da prova contra $35 \%$ do vespertino.

A análise comparativa do desempenho obtido nas duas avaliações comprova a elevação dos percentuais de acerto dos alunos dos dois turnos em 98. Considerando-se que este trabalho não realizou a análise comparativa das duas provas aplicadas, não se pode afirmar que este resultado revele, de fato, a melhora do desempenho dos alunos, visto que também pode ser devido a outros fatores, como, por exemplo, o nível de dificuldade das provas.

Por fim, apresentamos os resultados obtidos em Redação em 97 e 98.

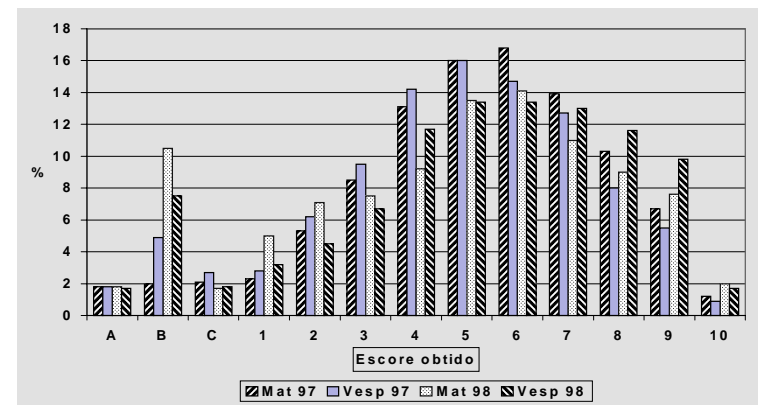

Figura 8.Escore obtido pelos alunos em Redação em 97 e 98

Nas provas de Redação foram atribuídas notas de zero a dez. A nota zero foi subdividida nas categorias 
(A, B e C), vinculadas, respectivamente, às situações em que a redação do aluno: não apresentava a estrutura solicitada; fugia do tema proposto e não era realizada. Os demais valores anotados no eixo $\mathrm{x}$ correspondem à nota obtida pelos alunos.

Com relação aos escores obtidos, a figura 8 permite observar um certo equilíbrio no desempenho dos alunos dos dois turnos em 97. Neste sentido, ela nos permite verificar que os alunos do matutino/97 tiveram um desempenho superior ao dos do vespertino, na medida em que obtiveram menos notas no intervalo de 0 a 4 e mais notas de 6 a 10 . Por outro lado, podemos também observar uma inversão nesta tendência na avaliação de 98. É interessante destacar que nesta avaliação o percentual de erros tipo A e C praticamente se mantiveram, enquanto os do tipo B (fuga do tema) apresentaram um aumento significativo.

No que se refere à comparação do desempenho dos alunos dos dois turnos, observamos na figura um leve deslocamento da curva para a direita e uma redução em sua altura em 98 . A figura traçada permite ainda observar o melhor desempenho dos alunos do matutino em 97 e o melhor desempenho dos alunos do vespertino em 98, quando focalizamos os percentuais de acerto no intervalo de 7 a 10 .

Utilizando como estratégia para comparação do desempenho o escore obtido pelos alunos, constatamos que os percentuais de alunos do mat./97, vesp./97, mat./98 e vesp./98 que obtiveram escores de zero a cinco foram, respectivamente: $51.1 \%$; $58.1 \%$; $56.3 \%$ e $50.5 \%$. Tais resultados indicam um aumento, na ordem de $5.2 \%$, dos alunos do matutino que obtiveram notas inferiores a 5.0, e uma redução, de $7.6 \%$, dos alunos do vespertino que obtiveram os mesmos escores.

Com relação à obtenção de escores superiores a 5.0, os alunos do mat./97 e vesp./98 apresentaram melhor desempenho, atingindo percentual próximo a $50 \%$, isto é, 48.9 e $49.5 \%$, respectivamente. Escores superiores (9.0 e 10.0) foram alcançados por uma porcentagem muito pequena de alunos (7.9 e $6.4 \%$ no matutino e vespertino/97, respectivamente, e $9.6 \%$ e $11.5 \%$ no matutino e vespertino/98).

No seu conjunto, estes dados permitem observar evidências de certa oscilação, para melhor e para pior, no desempenho dos alunos, o que nos permite alertar para a importância do desenvolvimento de ações, programas e projetos que contemplem a avaliação sistemática e continuada nas diferentes instâncias do sistema educacional paranaense, para além da simples avaliação do rendimento dos alunos em provas elaboradas e aplicadas ao nível do sistema.

\section{CONSIDERAÇÕES FINAIS}

O conhecimento da realidade do sistema, ao mesmo tempo em que nos revela suas fragilidades e contradições, nos convida a nos comprometermos com a luta pela transformação das condições aí existentes.

Por mais que questionemos as avaliações, sua amplitude, abrangência, estratégias e metodologias, elas têm o poder de retratar uma parte da realidade. Assim, o rendimento dos alunos não revela apenas o que eles sabem e não sabem, mas também o que sabem e não sabem os educadores e os profissionais que atuam no contexto escolar; além disto, revela também a atenção e o cuidado que a sociedade, na pessoa dos seus representantes e dirigentes, tem para com a formação e o desenvolvimento de suas crianças, jovens e adultos e para com a sua própria sobrevivência.

Com base na análise do rendimento dos alunos nas diferentes provas, constatamos que em aproximadamente $50 \%$ das questões os alunos alcançaram percentuais inferiores à média adotada no sistema. Ora, de que vale ter uma escola acessível, se ela continua excludente?

Sabemos que, ao longo do desenvolvimento da educação, vários saberes são associados à obtenção de bons resultados educacionais. Dentre eles, freqüentemente vemos serem destacados o saber e o saber-fazer dos docentes, ou seja, sua competência pessoal e profissional. Grande parte das iniciativas, ações e programas que visam à melhoria da qualidade educacional concentra-se, basicamente, nestes dois eixos. Por outro lado, a competência política do professor nem sempre tem sido valorizada e tido espaço para ser exercitada no interior do sistema.

Por esta razão, é também nosso objetivo mostrar a importância da conquista e ampliação do espaço de reflexão e análise, no seio da prática pedagógica; espaço que é, muitas vezes, relegado a segundo plano pelas próprias contingências pessoais, sociais e econômicas a que estão sujeitos os educadores e demais profissionais que atuam na educação. Assim, mais que responsabilizar os professores pela melhoria da qualidade da educação, devemos atribuir responsabilidade a todos os atores que atuam direta e indiretamente neste processo, incluindo entre eles os que idealizam e legislam sobre as questões educacionais, ou seja, os legítimos representantes da sociedade, porque eleitos democraticamente para representá-la.

A necessidade de superação desta situação ganha maior sentido quando consideramos que desde meados do século passado já se possuía certo consenso com relação às dificuldades e necessidades existentes no interior do sistema educacional. No entanto, a desvinculação entre o que se sabe e o que se $f a z$, ou entre o que se idealiza e se concretiza, tem persistido ao longo 
do tempo, fazendo com que paire sobre o sistema educacional uma certa apatia, indiferença, descrença $e$ descontentamento.

No sentido de tentar romper com este quadro, entendemos que o conhecimento e a reflexão acerca da realidade do sistema educacional, sob diferentes prismas e leituras, podem constituir em um elemento diferencial que pode provocar inquietação, reflexão e desejo de mudança, pois nada que se cria permanece imutável e resiste para sempre à crescente e inerente produção do conhecimento humano.

Assim, se a escola e o sistema educacional não são senão produto de uma construção social, histórica e coletiva, sua transformação e melhoria não podem advir senão por um movimento semelhante. Nossa opção consiste em deixarmos que as mudanças transcorram naturalmente ou tentarmos imprimir-lhes um ritmo e sentido desejados, com vistas a constituílas enquanto espaço de superação de desigualdades para a construção de uma sociedade mais justa e inclusiva.

\section{REFERÊNCIAS}

Aguerrondo, I. (1993). La calidad de la educación: ejes para su definición e evaluación. La educación. Revista Interamericana de Deserrollo Educativo, 37(116), 561-578.

Candeias, A. (1995). Políticas educativas contemporâneas: críticas e alternativas. Educação e Realidade, 20(1), 154-189.

Freire, P. (1987). Pedagogia do oprimido. Rio de Janeiro: Paz e Terra. Ghiraldelli Jr., P. (1992). História da educação. São Paulo: Cortez.

Good, T. L. (1995). As escolas marcam a diferença: evidências, críticas e novas perspectivas. Em A. Nóvoa (Org.), As organizações escolares em análise. (2 ${ }^{\mathrm{a}}$ ed., 77-98) Lisboa: Publicações Dom Quixote.

Gorni, D. A. P. (1999). Sistema estadual de educação do Paraná: qualidade e avaliação. Tese de Doutorado Não-Publicada, Programa de Pós-Graduação em Educação, Universidade Estadual Paulista, Marília

Gorni, D. A. P. (2002). Reestruturação do ensino fundamental do Paraná após a abertura democrática do Brasil: retrospectiva e perspectivas. Londrina, Eduel.

Gorni, D. A. P., Hoshiro, R. H., Kuasne, H. \& Mattei, K.P. (2003). Reestruturação do ensino fundamental do Paraná: qualidade $e$ avaliação nas proposições do sistema e nas escolas estaduais (Relatório de Pesquisa). Londrina: CPG/UEL.

Hadji, C. (2001). A avaliação desmistificada. Porto Alegre: ArtMed.

Hoffmann, J. M. L. (1991). Avaliação: mito \& desafio: uma perspectiva construtivista. Porto Alegre: Mediação.
Hofmann, J. M. L. (1993). Avaliação mediadora: uma prática de construção da pré-escola à universidade. Porto Alegre: Mediação.

Luckesi, C. C. (1996). Avaliação da aprendizagem escolar. São Paulo: Cortez.

Mezomo, J. C. (1997). Educação e qualidade total: a escola volta às aulas. Petrópolis: Vozes.

Nóvoa, A. (1995). Para uma análise das instituições escolares. Em A. Nóvoa (Org.), As organizações escolares em análise. (2 ed., 13-44). Lisboa: Publicações Dom Quixote.

Penna Firme, T. (1994). A avaliação: tendências e tendenciosidades. Ensaio: Avaliação e Políticas Públicas em Educação, 1(2), 5-12.

Purkey, S. C. \& Smith, M. S. (1983). Effective schools: a review. Elementary School Journal, 83(4), 427-52.

Perrenoud, P. (1999). Avaliação: da excelência à regulação das aprendizagens - entre duas lógicas. Porto Alegre: Artes Médicas Sul.

Rampazzo, S. R. R. (2002). Análise da prática avaliativa de professores em formação com mídias interativas. Dissertação de Mestrado Não-Publicada, Programa de Pós-Graduação em Educação, Universidade Estadual de Londrina.

Resende, L. M. G. (2001). O sujeito reflexivo no espaço da construção do projeto político-pedagógico. Em: I. P. A. Veiga \& M. Fonseca (Orgs.), As dimensões do projeto político-pedagógico: novos desafios para a escola (pp. 239-256). Campinas, Papirus.

Sa Chaves, I. (2000). Portfólios reflexivos: estratégias de formação e de supervisão. Portugal: Universidade de Aveiro.

Saviani, D. (1997). A nova lei da educação: trajetória, limites e perspectivas. Campinas: Autores Associados.

Saviani, D. (2000). Da nova LDB ao plano nacional de educação: por uma política educacional. Campinas: Autores Associados.

Simons, H. (1993). Avaliação e reforma das escolas. Em A. Estrela \& A. Nóvoa (Orgs.), Avaliações em educação: novas perspectivas (pp. 155-170). Portugal: Porto.

Valente, S. M. P. (2002). Parâmetros curriculares nacionais $e$ avaliação nas perspectivas do estado e da escola. Tese de Doutorado Não-Publicada, Programa de Pós-Graduação em Educação, Universidade Estadual Paulista, Marília.

Vasconcelos, C. S. (1994). Avaliação: concepção dialéticolibertadora do processo de avaliação escolar. São Paulo: Libertd.

Vasconcelos, C. S. (1995). Algumas observações sobre a mudança na prática da avaliação. Revista da Educação AEC, 24(9), 86-97.

Vianna, H. M. (1997). Avaliação educacional e o avaliador. Tese de Doutorado Não-Publicada, Programa de Pós-Graduação em Psicologia da Educação, Pontifícia Universidade Católica. São Paulo.

Zabala, A. (1998). A prática educativa: como ensinar. Porto alegre: Artmed.

Recebido em 12/03/2004 Aceito em 30/07/2004

Endereço para correspondência: Doralice Aparecida Paranzini Gorni. Universidade Estadual de Londrina - Departamento de Psicologia Social e Institucional, 86051990, Londrina - PR. E-mail: doragorni@onda.com.br 